\title{
New Control Strategies for Longwall Armored Face Conveyors
}

\author{
Alan R. Broadfoot, Member, IEEE, and Robert E. Betz, Member, IEEE
}

\begin{abstract}
This paper investigates a new control approach for longwall armored face conveyors (AFC's) using variable-speed drives (VSD's). Traditionally, AFC's have used fixed-speed or two-speed motors, with various mechanical solutions employed to try to solve the problems that this causes. The VSD approach to the control problem promises to solve all the significant problems associated with the control of AFC's. This paper will present the control algorithms developed for a VSD-based AFC drive system and demonstrate potential performance via computer simulation. A full discussion of the problems involved with the control of AFC's can be found in the companion paper [1].
\end{abstract}

Index Terms-Armored face conveyor, inverters, vector control.

\section{INTRODUCTION}

A RMORED FACE conveyors (AFC's) are used in longwall mining to transport the coal cut from the face by the shearer to the rubber conveyor at one end of the face. This seemingly crude mechanical setup is actually quite a complex electromechanical system, which, under current control regimes, exhibits a number of operational problems. These problems are discussed in detail in a companion paper [1] and will only be briefly reiterated here.

AFC problems can be broadly characterized into electrical problems and mechanical problems. It should be noted that problems in these two categories interact.

The main electrical problems are the following:

1) voltage dip due to high starting currents;

2) possible stalling due to externally imposed voltage dips;

3) differential in the voltage supplied to the two motors in a dual-drive system;

4) possible large torque pulsations on AFC startup;

5) variations in motor characteristics;

6) motor thermal effects.

The main mechanical problems that affect AFC operation are the following:

1) variations in gearbox specifications;

Paper PID 97-27, presented at the 1996 Industry Applications Society Annual Meeting, San Diego, CA, October 6-10, and approved for publication in the IEEE TRANSACTIONS ON INDUSTRY APPLICATIONS by the Mining Industry Committee of the IEEE Industry Applications Society. Manuscript released for publication October 13, 1997.

A. R. Broadfoot is with AMP Control SWG Pty. Ltd., Newcastle, NSW 2322, Australia.

R. E. Betz is with the Institute of Energy Technology, Department of Electrical Energy Conservation, Aalborg University, DK-9220 Aalborg East, Denmark, on leave from the Department of Electrical and Computer Engineering, University of Newcastle, NSW 2308, Australia.

Publisher Item Identifier S 0093-9994(98)02565-1.
2) variations in the sprocket ratios and efficiencies;

3) variations in the performance of fluid and wet clutch couplings.

The operational consequences of the above electrical and mechanical problems are as follows.

1) AFC systems are prone to stalling, especially when started under full-load conditions.

2) The motors in dual-drive AFC systems do not share the AFC load evenly, and this results in stalling and/or reduced plant life due to excessive stress on the components of the more highly loaded drive system.

Remark 1: The net result of these problems with AFC systems is lost production due to stalling of the conveyor or drive system component failures.

The remainder of this paper will concentrate on the problems with dual-drive AFC's, as these are the most common form of drive for the longer faces that are common these days. Furthermore, the problems associated with the singledrive AFC's are a subset of those for the dual-drive AFC's. A solution to the above problems will be shown, in this paper, to be the use of inverter-fed induction machines. This technology is able to give induction machines very similar characteristics to chopper-fed separately excited dc machines, i.e., high bandwidth accurate torque control. This ability inherently means that induction machines also have a variable-speed capability, which can be useful in some circumstances.. This paper will investigate one particular possible implementation of the AFC control system.

\section{Control Objectives}

The objectives for the AFC controller to be designed are the following:

1) control the maingate and tailgate motors, so that they evenly share the load on the AFC, despite component mismatches in the drive train and different voltage supplies to the motors;

2) allow the AFC to start successfully under full-load conditions with a reduced voltage supply;

3) minimize voltage dips caused by large starting currents;

4) prevent stalling of the AFC when externally imposed voltage dips occur;

5) eliminate the fluid or wet clutch couplings from the drive train;

6) control the AFC velocity at some user-defined value subject to programmed current limits. 
If these control objectives are achieved, then the problems referred to in [1] would be eliminated.

\section{Possible Solution APPROACHES}

There have been a number of attempts to solve the stalling and load-sharing problems of AFC conveyors using a combination of electrical and mechanical techniques. It may be beneficial to review some of these at this stage.

Remark 2: Overdesign of all the AFC system components has been traditionally used as a technique for overcoming AFC problems. However, this results in higher capital costs and, in some cases, it can exacerbate the voltage supply problems.

\section{A. Current Solution Approaches}

In order to start a fully loaded AFC, one clearly must have the necessary torque available. A variety of techniques have been used with varying degrees of success in order to obtain this starting torque. An important requirement for any such scheme is that it be very robust, because of the high cost of breakdowns.

Three traditional techniques that have been used to obtain large starting torques from direct-on-line (DOL) start induction machines are as follows:

1) wound-rotor machines with external resistance or slip energy recovery control;

2) double-cage or high-resistance rotor machines;

3) two-speed motors.

Let us now consider each of these options.

1) Wound-Rotor Machines with External Resistor Bank: The wound-rotor machine is not a desirable option in a mining environment, due to the presence of brushes. Furthermore, the wound rotor itself is not as robust as the rotor of a squirrel-cage induction machine and is considerably more expensive. The presence of the external resistor bank would present problems in the AFC application, due to the physical limitations on the space available at the coal face. There is also a problem in getting rid of the heat produced. The low energy efficiency of this scheme is also undesirable.

An alternative configuration for the wound-rotor machine is the use of a power electronic converter, instead of the resistor bank. This approach alleviates the efficiency and heat dissipation problems inherent with the resistor bank approach, as the slip energy from the rotor is fed back into the mains supply. If a machine has a limited speed range, then the slip recovery approach has the advantage that the inverter only has to be rated for the slip power, which is substantially less than the rated power under these conditions. However, due to the operational constraint that the AFC drive machines have to be able to produce full-load torque at zero speed, this advantage is lost. The slip recovery inverter has to be rated at the rated power of the machine. Consequently, the potential cost saving from partially rated power electronics is lost.

2) Double-Cage and High-Rotor-Resistance Machines: The use of a double cage in a squirrel-cage induction machine is a well-known technique for obtaining higher starting torque, while, at the same time, operating at small slip in the steadystate operating condition. Similarly, a high-resistance rotor can achieve similar starting torque improvements, but these machines operate at higher steady-state slip values compared to the double-cage solution. This means that the operating speed will be lower for this type of machine for a given input supply frequency, and the efficiency will be less, due to higher rotor losses. Both the double-cage and high-resistance rotor solutions have an advantage over a conventional induction motor, in that the starting currents will be lower and, consequently, the voltage drop due to the supply cables will be less.

These advantages have lead to the use of the double-cage induction machine in many AFC drive systems. However, this approach still has significant disadvantages. The double-cage machine still suffers from significant starting-current problems, and the consequent voltage dips, although they are less than the normal induction machine under DOL start conditions.

3) Two-Speed Machines: Two-speed induction machines effectively have two sets of windings with different pole numbers. Generally, the machine is started with the high pole number winding (which will give the maximum torque), and there is a switch at some nominated speed to the lower pole number winding. This winding will allow the machine to reach the desired operational speed.

Two-speed machines still have many of the problems that are present with the normal induction machine. The twopole number structure does give better starting torque compared to the normal induction machine, but, the overcurrent problems during start are still present. In addition, the twospeed machine requires the use of a changeover contactor, which is an extra capital expense and another source of potential component failure. At start, the machine exhibits the large torque pulsations of the conventional machine, so fluid couplings are still required to prevent these from damaging the gearbox and AFC. The speed changeover has the property of introducing additional torque transients. The AFC will also slow during the changeover period, and there is the possibility that the motor can stall, because of the lower torque that is available immediately after the winding changeover.

Remark 3: All of the above techniques have the common problem that they do not address the startup inrush current problem, which results in substantial voltage drop in the supply to the machine. In addition, they do not offer any viable techniques for accounting for gearbox and voltage mismatches between the drive ends.

4) Mechanical Solutions: Mechanical solutions that have been applied to AFC's in an effort to overcome the problems are the following:

a) fluid couplings;

b) wet clutch couplings.

5) Fluid Couplings: Fluid couplings traditionally have been the most popular method of applying gradual torque to the AFC when the drive machines are started DOL. They also have the advantage that they allow the induction machines to build up speed reasonably rapidly, since the AFC load does not appear on the motor shaft at low shaft speeds, because of the slip characteristics of the couplings. In addition, fluid couplings prevent the transmission of the large transient torque pulsations present at startup to the gearbox. 
Normal fluid couplings do not allow for compensation of the mismatches in the AFC drive system. Therefore, in their traditional form, they cannot perform load balancing. Another solution that has been investigated in recent years is variable-fill fluid couplings. In order to control the torque being applied to the AFC, the fluid fill of the coupling is varied under the control of a programmable logic controller (PLC). These couplings are purposely built for such applications and use water as the fluid medium. This approach has had some success, in that compensation can be made for some of the differences between both drive ends. However, it is an inelegant approach compared to the alternative techniques developed later in this paper. For example, the use of water results in additional complexity around the longwall face because of cooling water reticulation requirements. In addition, fluid couplings are a "weak" point in the drive system and are prone to overheating and failure.

6) Wet Clutch Couplings: An alternative mechanical coupling technique that has been applied in recent years is the wet clutch coupling. This is essentially a clutch, which is water cooled, with the plate pressure being altered via hydraulics controlled from a PLC, so that both the torque transmitted to the load and the speed of the shaft can be varied. As with the variable-fill fluid coupling, this technique is crude in concept. It obviously has problems in the efficiency area, as well as practical difficulties in relation to the water supply for cooling. In addition, the coupling tends to be rather bulky, making it difficult to install or remove from the face area if maintenance is required.

Remark 4: Both of the above mechanical techniques, while they do solve some of the AFC drive problems, are very inelegant, inefficient, high maintenance, and are potentially unreliable.

\section{B. Modern Control Approaches}

The control objectives of Section II indicate that the use of a variable-speed drive (VSD) system may be appropriate. Modern VSD's have overcome the reliability problems they had 15 years ago and are widely used in most other industries. The coal industry, being rather conservative and inclined to cling to technologies that seem to have worked in the past, has been slow to adopt this technology. VSD's coupled with computer control offer the sophistication required to achieve all of the desired objectives.

Assuming a power electronic supply, there are several different motor/power electronic configurations that can be considered, including the following:

- wound-rotor/doubly fed motor with inverter;

- conventional squirrel-cage induction machine.

The first of these was addressed in Section III-A-1 and will not be considered further.

The remainder of this paper will concentrate on the conventional squirrel-cage induction machine fed from a fully rated inverter. This is a standard VSD system configuration. A block diagram showing the general configuration of a VSD-based AFC drive system, contrasted with a conventional drive, is shown in Fig. 1. Notice that the fluid coupling is no longer

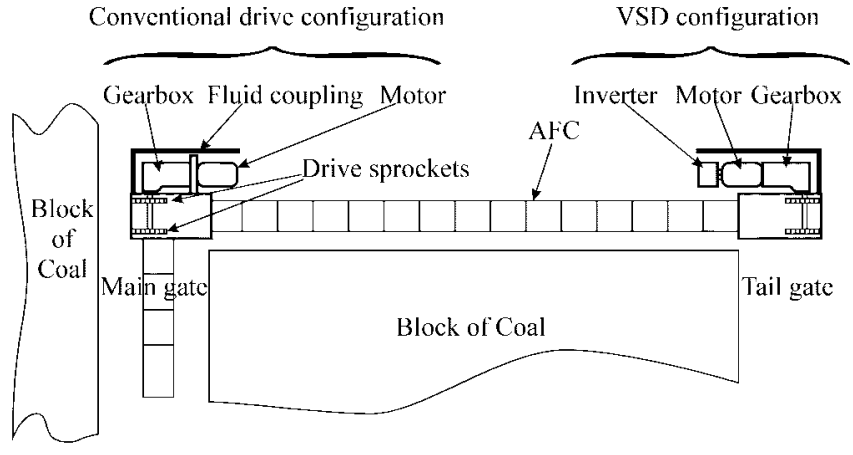

Fig. 1. AFC drive system configurations.

needed in the drive train. It has essentially been replaced by the inverter.

The inverter could be a conventional inverter using an uncontrolled front-end rectifier, but, in the near future, it is more likely to have a pulsewidth modulation (PWM)-based rectifier. This will be required, in order to satisfy the new IEC 555 regulations. The use of the front-end rectifier also has the additional advantage that one cannot only obtain unity power factor at the input to the rectifier, but the power factor can be controlled to some user-defined value. This allows the possibility of supplying var voltage support to the weak supply at the mine face. PWM rectifiers can also satisfy the stricter harmonic requirements that are becoming mandatory around the world.

\section{CONTROL Strategies}

In the VSD drive system configuration, the maingate and the tailgate motors have their own individual torque controllers. These require coordination, in order to drive the AFC in a stable manner. We shall look initially at the control strategies that can be used by the individual controllers and then consider the coordination issue.

The control objectives were outlined in Section II. There are two main options that are available for the controllers, a quasi-steady-state-based strategy and the vector field-oriented control strategy.

\section{A. Quasi-Steady-State Control Strategies}

Quasi-steady-state control refers to a category of control strategies that involve applying a voltage proportional to the electrical frequency. The control is derived by considering the machine to be in steady state, i.e., the steady-state electrical model of the machine is used to think about and derive the controllers. The current into the machine (and, hence, the torque) is controlled by using the slip frequency of the machine. To increase torque, the applied frequency is increased, the increase being limited by the maximum slip frequency of the machine. A block diagram for one particular strategy is shown in Fig. 2. Notice that it is possible to have a speed control loop, so that the speed normally lost due to the slip frequency can be accounted for under steady-state conditions. 


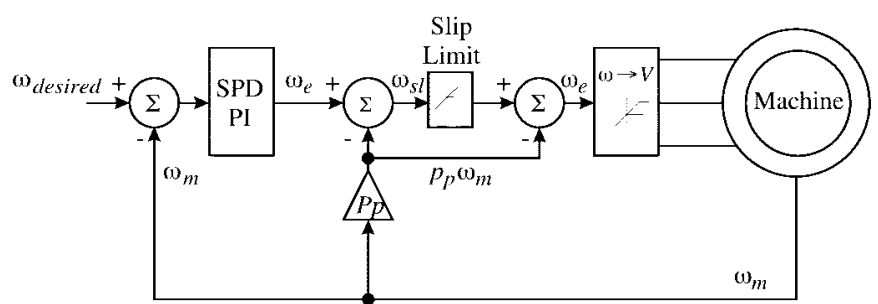

Fig. 2. Block diagram of a quasi-steady-state controller for an induction machine.

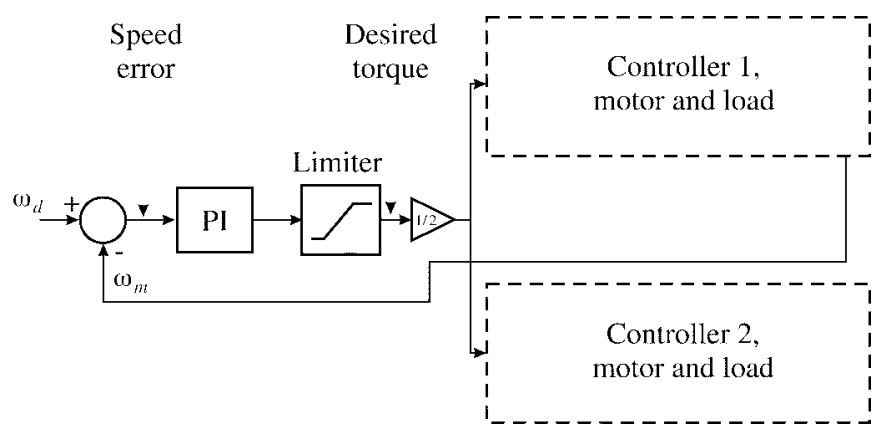

Fig. 3. General topology of the control system.

A number of variants of quasi-steady-state control strategies is possible, however, all of them have similar characteristics. For example, there are still torque transients during the startup and acceleration of the machine, altough these are much less than with a DOL start. The slip frequency of the machine is a controlled quantity, which indirectly controls the magnitude of the sinusoidal current drawn from the supply. Therefore, the voltage drop problems associated with DOL starts are largely alleviated. Mismatches between the maingate and tailgate drives can be compensated for during steady-state operation if one can obtain a good estimate of the torque produced by each of the machines. However, the transient performance of these strategies is inferior to the vector-controlled strategies to be discussed next, meaning that, during start, the two drives might not be as effective as they could be because of out-ofphase torque transients. It should also be noted that because these controllers control torque via the slip frequency, they are subject to the same pullout torque limits as an uncontrolled induction machine.

\section{B. Field-Oriented Vector Control}

Now let us consider the field-oriented control approach. The overall structure of the dual-machine control problem is shown in Fig. 3. As can be seen, there is only one speed reference used for both the controllers. If the AFC is considered to be a distributed elastic system, then this approach could possibly lead to transiently different shaft angular velocities and instability. However, the presence of pretensioning implies that there is no additional stretch in the chain with load changes and, consequently, the angular velocities of the motors have to be transiently the same. In addition, under normal conditions, the speed controller bandwidth would not be very high, ensuring that there are no sudden torque transients when there are load changes on the AFC. Detailed investigation has been made of the possibility of oscillation building up because of the decentralized nature of the controllers, and it was found the high AFC friction (especially when loaded with coal) together with the pretensioning of the chain eliminated oscillation problems.

The individual motor controllers are based on the direct field-orientation principle. This is a well-known highperformance control strategy [6]. An alternative and equally valid approach is indirect field-oriented control, which does not involve the use of a flux model. The key performance aspect of field-oriented control that is of particular interest in this application is that it makes an induction machine behave as though it is a dc machine. Therefore, very precise control over the torque is obtained, and torque pulsations that occur with DOL starting do not occur. Torque control implies current control and, consequently, the overcurrent problems inherent in DOL starts are eliminated.

Fig. 4 shows the essential features of a general direct field-oriented vector control algorithm. Notice that the direct field-oriented algorithm relies on a flux model to ascertain the position of the rotor flux vector (hence, the name "field oriented"). All the control calculations are carried out in a synchronously rotating reference frame aligned with the rotor flux vector. Accurate alignment is critical if the best possible performance is required from the controller. The flux model is the main point in this control strategy where parameter dependence enters, as the flux estimator is critically dependent on accurate knowledge of the machine rotor resistance. This value varies substantially during machine operation as a result of temperature rise in the rotor. Much research over the last ten years has been devoted to finding robust rotor resistance estimators for direct and indirect field-oriented control algorithms. These problems have been largely solved, and field-oriented controllers are now finding widespread acceptance in many applications that were once the province of the dc machine. It should be noted that, for the AFC application, the speed control section of the controller is generic between the controllers at the tailgate and the maingate.

The key control equations used in direct field oriented control are [6]

$$
\begin{aligned}
T_{r} \frac{d\left|i_{m r}\right|}{d t}+\left|i_{m r}\right| & =i_{s x} \\
\tau_{e} & =\frac{3}{2} \frac{L_{m}^{2}}{L_{r}}\left|i_{m r}\right| i_{s y} \\
J \omega_{r}+f \omega_{r} & =\tau_{e}
\end{aligned}
$$

where

$T_{r}=L_{r} / R_{r}$. rotor time constant;

$\left|i_{m r}\right| \triangleq$ rotor magnetizing current;

$i_{s x} \triangleq$ magnetizing component of the stator current;

$i_{s y} \triangleq$ torque-producing component of the stator current. The remainder of the definitions are obvious. Notice that the flux in the machine $\left(L_{m}\left|i_{m r}\right|\right)$ can be controlled independently of the torque. This is the key feature of field-oriented control.

It could be argued that a field-oriented control strategy is overkill for this application, since servo-like performance is not required. However, the complete absence of torque 


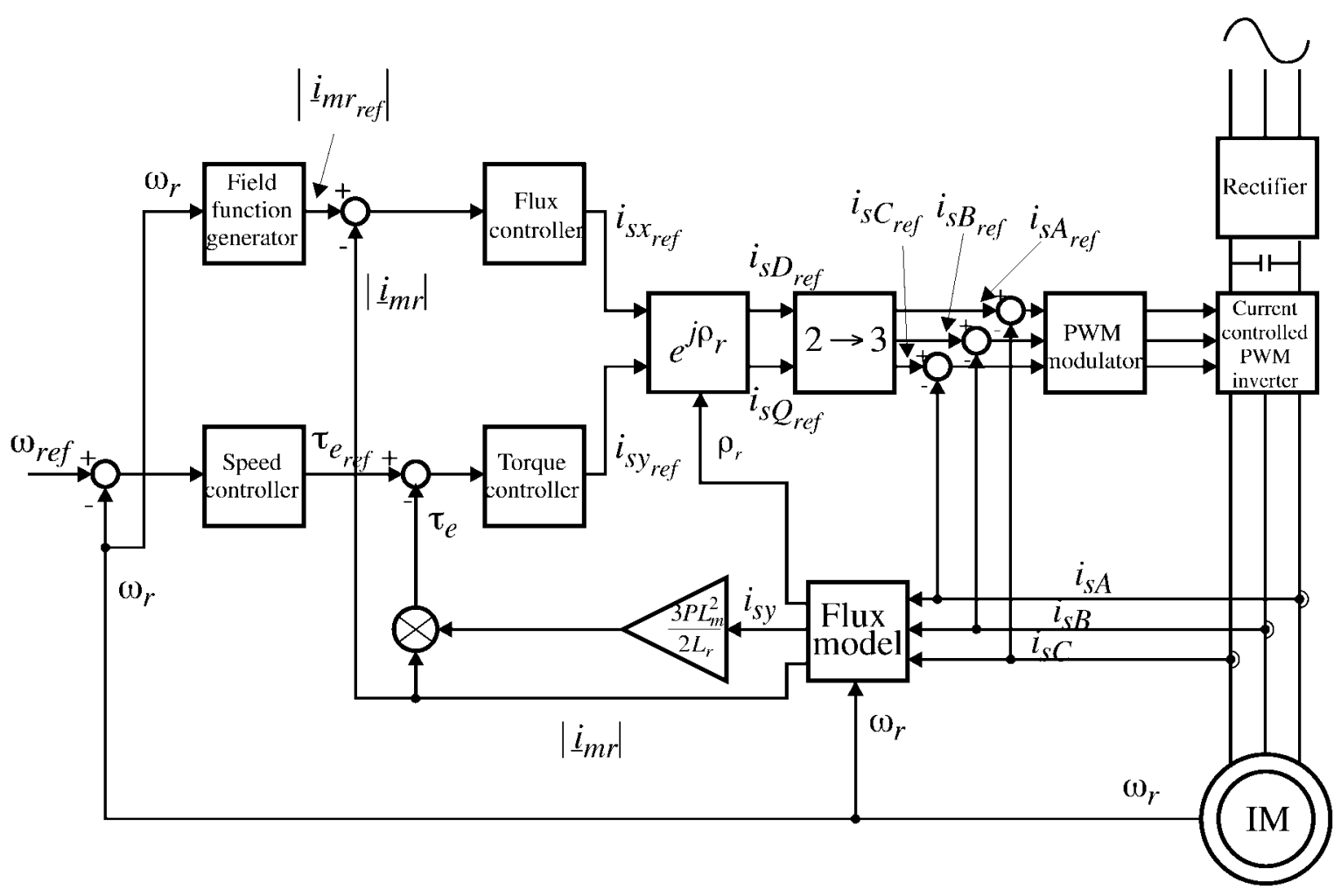

Fig. 4. Block diagram of direct field-oriented vector controller.

pulsations coupled with very accurate control of the torque and motor currents are inherent characteristics of this control technique and are beneficial in this application. In addition, as can be seen from (2), vector control allows large shortduration torques to be produced without exceeding the pullout torque of the machine (there is no concept of pullout torque in a vector control strategy). This is very advantageous when starting heavily loaded AFC's and is a distinct advantage over the pseudo-steady-state constant voltage/frequency (V/F) ratio control strategies. Furthermore accurate torque control is also a benefit at AFC startup, as the two machines will "pull together" during the initial acceleration phase. The inherent electromagnetic torque estimate available with field orientation is an advantage for a control strategy that is attempting to produce the same torque from two motors with parameter mismatches in the machines and the drive train components. Finally, the cost of implementing a field-oriented control strategy is a minimal increment above the cost of implementing the constant V/F strategy.

\section{Simulation Results}

Due to the fact that no longwall in Australia has the necessary equipment to carry out the experimental evaluation of these proposed solutions, the above assertions were tested by creating a simulation model for the AFC and its motors using the SIMULINK dynamic systems simulation package. Every effort was made to use realistic parameters for the motors, supply lines, and gearboxes. The parameters used appear in Table I.

The plots are arranged in two groups; one group shows the effects of mismatch on various performance parameters of the
TABLE I

SYSTEM PARAMETERS

\begin{tabular}{l|c}
\hline Parameter & Parameter Value \\
\hline \hline Rated power & $500 \mathrm{hp}$ \\
\hline Rated speed & $1478 \mathrm{r} / \mathrm{min}$ \\
\hline Poles & 4 \\
\hline$R_{s}$ & $0.262 \Omega$ \\
\hline$L_{s}$ & $0.1465 \mathrm{H}$ \\
\hline$L_{m}$ & $0.1433 \mathrm{H}$ \\
\hline$L_{r}$ & $0.1465 \mathrm{H}$ \\
\hline$R_{r}$ & $0.277 \Omega$ \\
\hline Cable (maingate) & $25 \mathrm{~m} \mathrm{of} 50 \mathrm{~mm}^{2} \mathrm{EPR}$ \\
\hline Cable (tailgate) & $225 \mathrm{~m}$ of $50 \mathrm{~mm}^{2} \mathrm{EPR}$ \\
\hline Gearbox mismatch & $1 \%$ \\
\hline
\end{tabular}

$\mathrm{AFC}$, and the second group demonstrates the improvement that is obtained using the vector-controlled drive system.

\section{A. DOL Start Plots}

Fig. 5 is a plot of the maingate torque for the case where there is a $1 \%$ mismatch between the maingate and the tailgate gearbox ratios. The dashed plot is the torque if there are no mismatches in the gearboxes, and it is called the ideal torque. Notice that the mismatch has resulted in the maingate motor being more highly loaded during steady-state operation. If a similar plot is made for the tailgate torque, it is found that the torque is lower than that for no mismatch. The $1 \%$ gearbox mismatch results in an $18 \%$ difference between the maingate and tailgate torques. Clearly, the loading on the machines is highly sensitive to this parameter. Fig. 6 shows the error between the ideal and actual torque for the maingate. Notice that the error is small during the transient as the AFC 


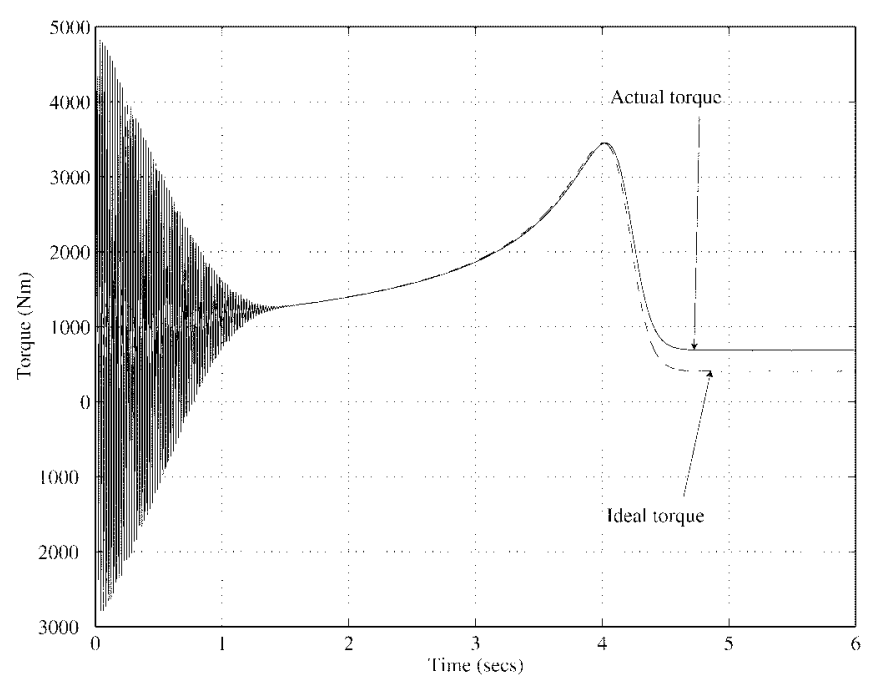

Fig. 5. Maingate torque characteristic with gearbox mismatch.

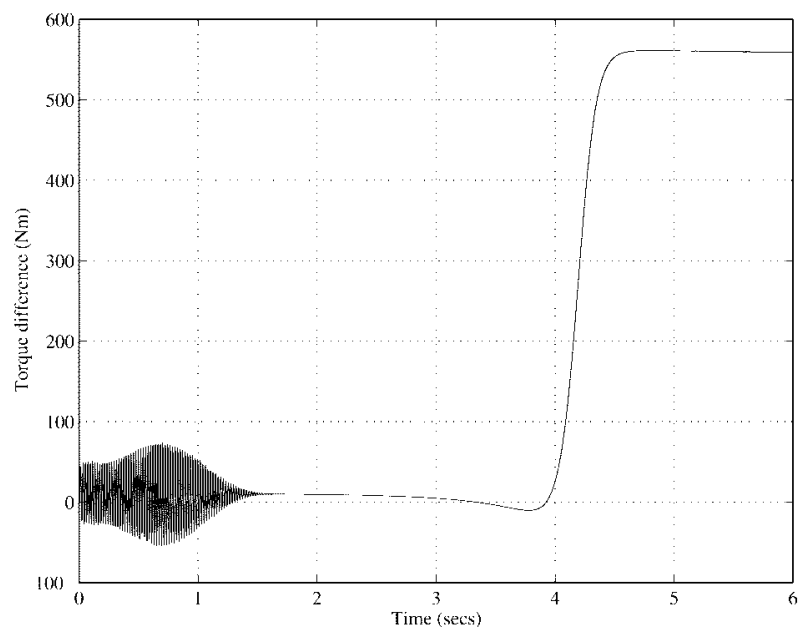

Fig. 6. Error between actual and ideal maingate torques with gearbox mismatch.

accelerates, but becomes larger in steady state. This is due to the lack of torque sensitivity with respect to the slip at high slip values and high sensitivity at low slip.

Fig. 7 is the plot of the maingate torque when there is a voltage mismatch between the maingate and tailgate motors. This voltage mismatch represents the voltage drop across the face to the tailgate motor. Notice that the torque speed characteristic is displaced by approximately $1 \mathrm{~s}$, due to the slower AFC acceleration times. This results from the lower total torque being produced by the machines under this condition. Fig. 8 is the similar diagram for the tailgate. Notice that the peak torque that this machine is capable of producing is degraded by the lower voltage available.

Fig. 9 shows the torque error between the maingate and tailgate motors under the voltage mismatch condition. Notice that this curve is the dual of the gearbox mismatch case, in that the maximum error now occurs during the acceleration period, and there is little error during steady state. The reason

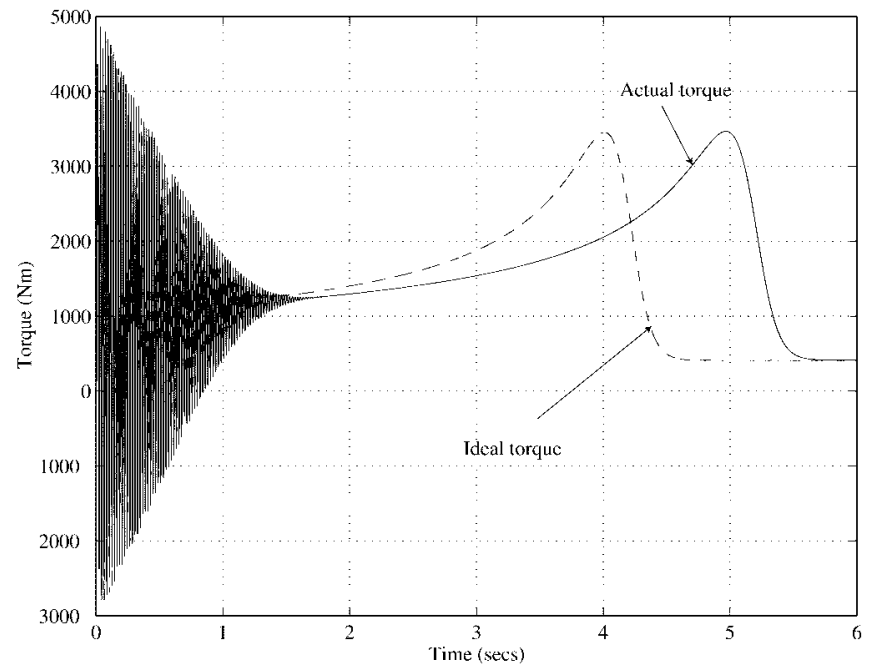

Fig. 7. Actual and ideal maingate torque with voltage mismatch.

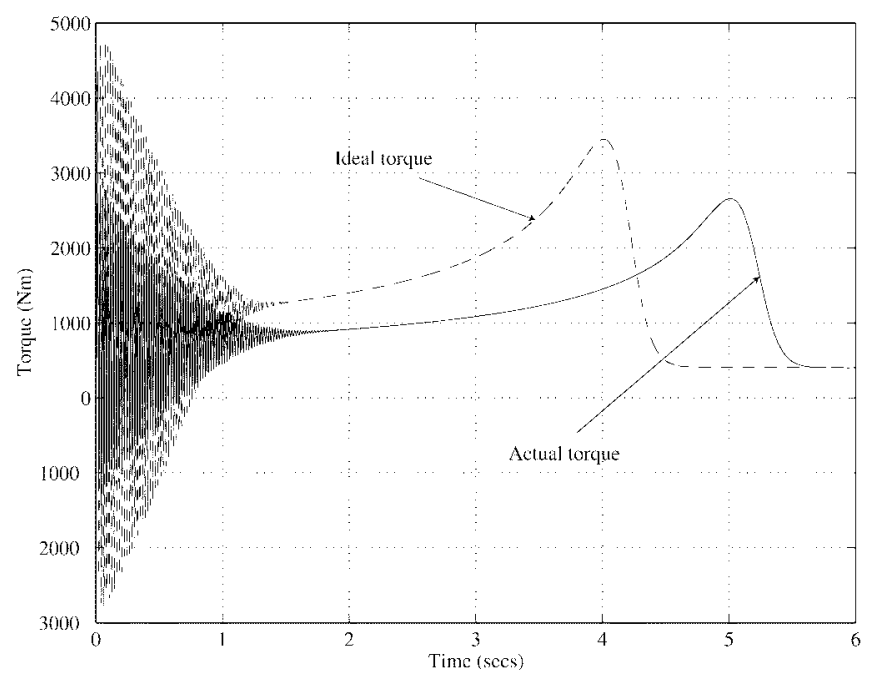

Fig. 8. Actual and ideal torque characteristics for the tailgate with voltage mismatch.

for this is that, during acceleration, the maximum torque for the motor is being demanded, and this is directly related to the voltage available at the machine terminals. In steady state, the torque demand is well below the maximum, and the nature of the steady-state torque slip characteristic for the induction machine means that the torque error will be small under this condition.

\section{B. Vector-Controlled Machine Plots}

Fig. 10 shows the maingate and tailgate motor torque plots when the machines are being controlled by a vector controller. There is a $1 \%$ gearbox mismatch between the gearboxes. The two plots are identical, demonstrating that there is virtually exact load sharing occurring between the machines. This can be seen in Fig. 11, which shows the torque error between the two machines. 


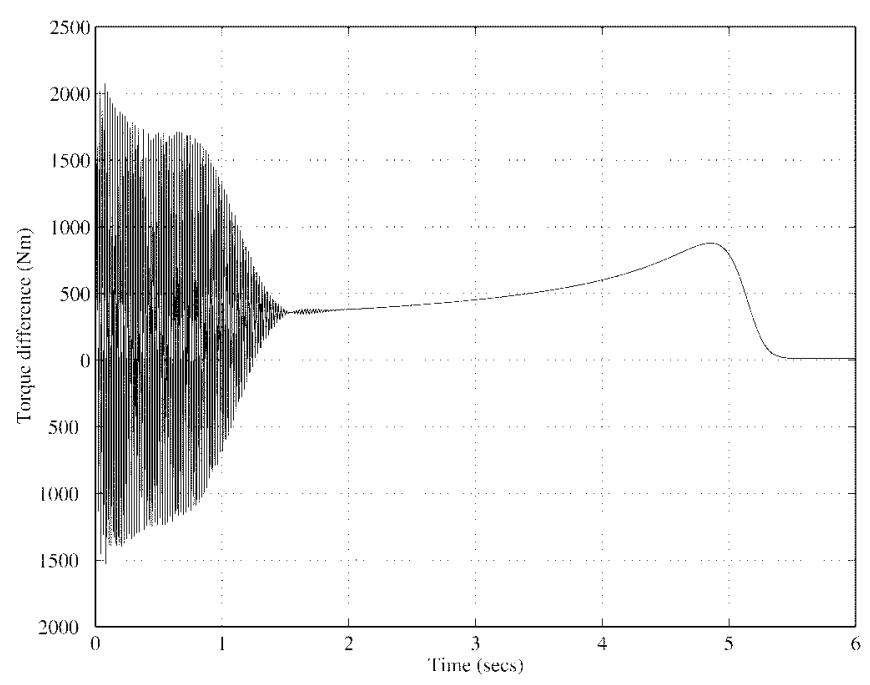

Fig. 9. Maingate/tailgate torque error with voltage mismatch.

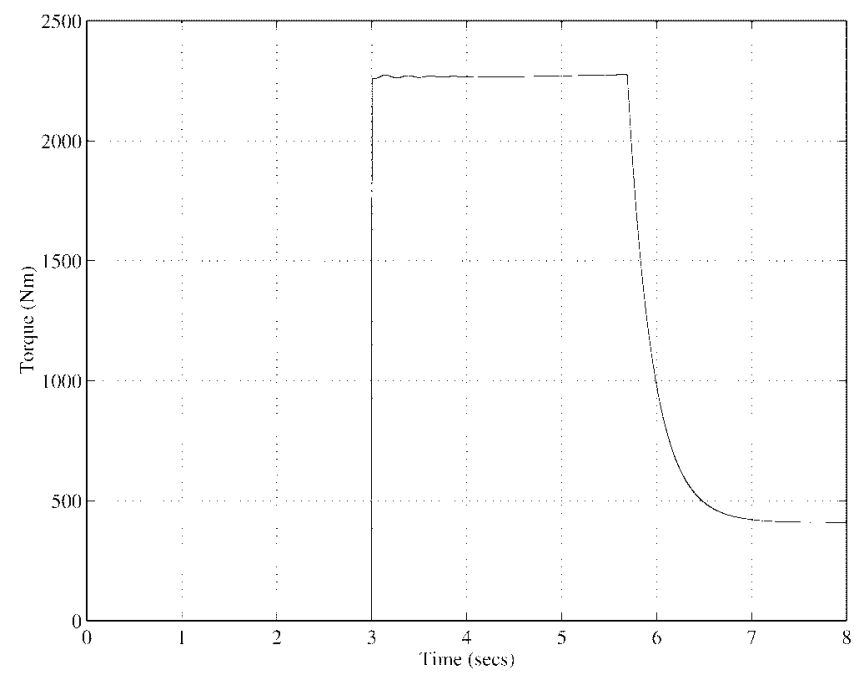

Fig. 10. Torque plots for the vector-controlled AFC drives.

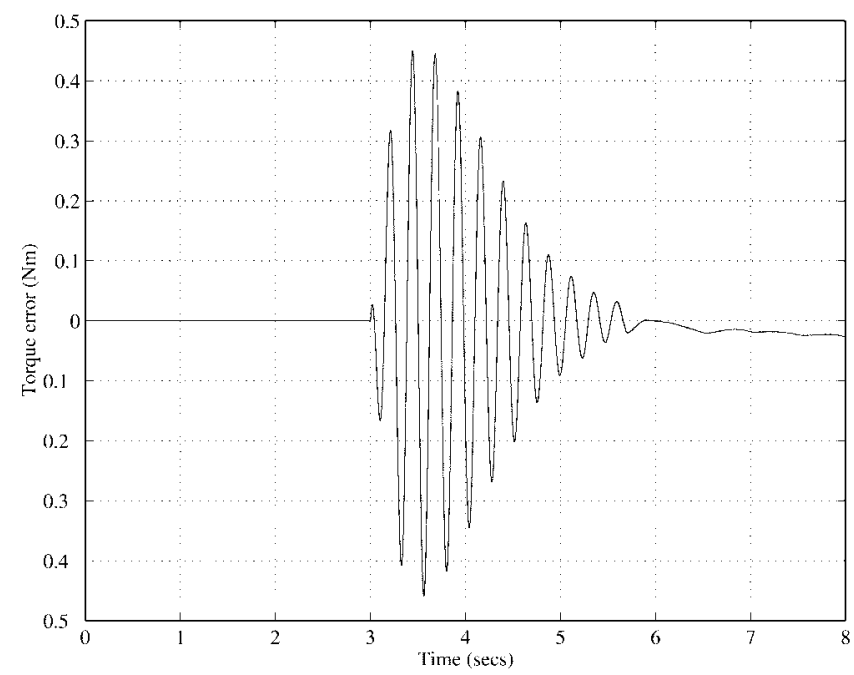

Fig. 11. Error between the maingate and tailgate motor torques under vector control when there is gearbox mismatch.

Fig. 12 shows the vector-controlled maingate and tailgate torque plots when there is a voltage mismatch between the

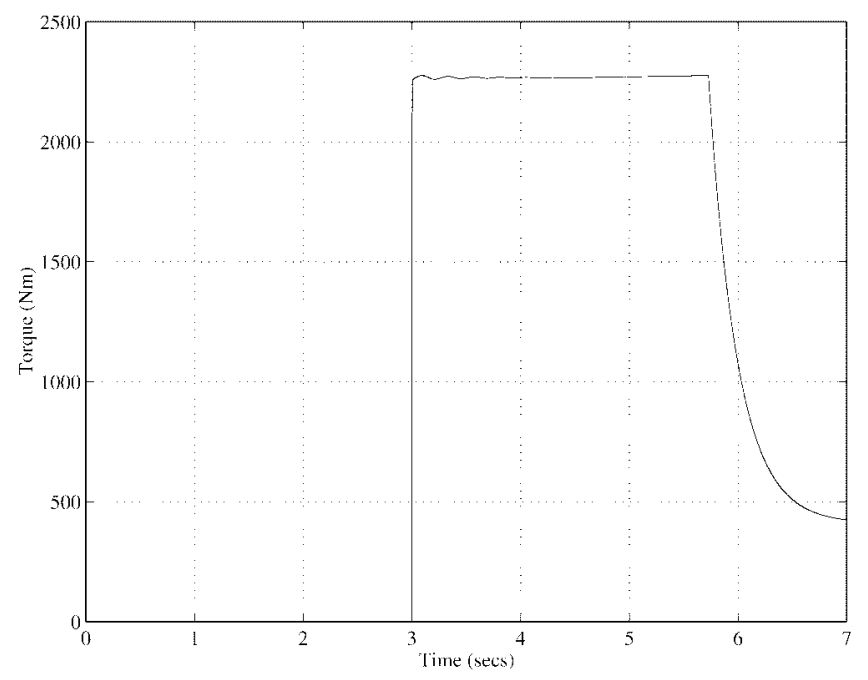

Fig. 12. Torque plots for vector-controlled machines with voltage mismatch.

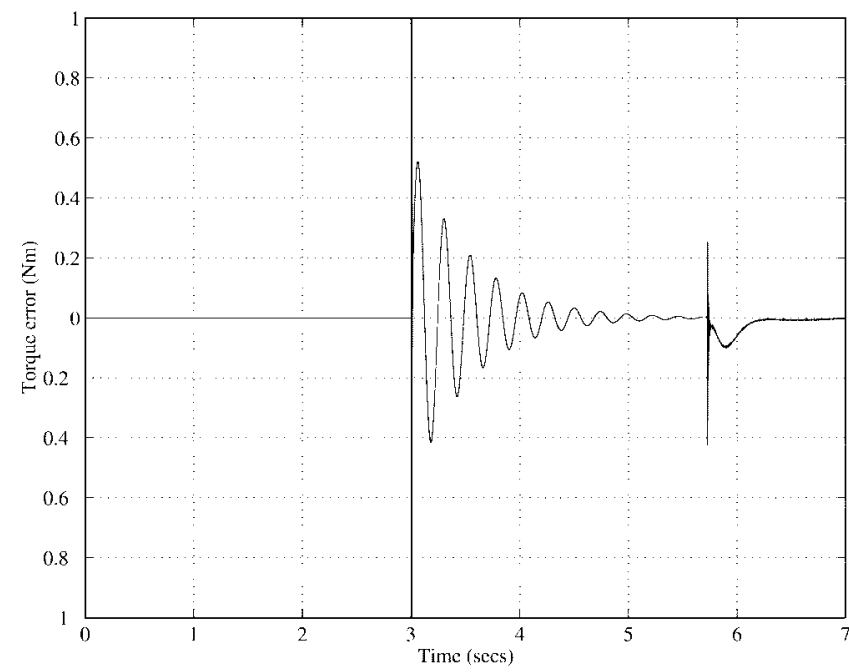

Fig. 13. Torque plots for vector-controlled machines with gearbox mismatch.

tail and main motors. As with the previous case, the torque matching is so exact that the two plots lie on top of each other. Fig. 13 shows the error between the maingate and tailgate motors. The percentage error is very small. In fact, most of the error seen in the plot is due to the fact that the control was started before the flux in the machine had stabilized. The vector control for all these cases included the effects of rotor heating. The rotor resistance was changing by $50 \%$ in a 150 -s interval. Over the duration of the simulations, the change would have been relatively small and, hence, it has had little effect on the performance of the controller. However, over longer periods of time, rotor resistance compensation would be necessary if good transient performance is required.

\section{Comparison}

It is clear from the plots shown that the torque produced by the vector controller rises rapidly to the desired value. Thus, the full torque is being applied to the load virtually instantly. Consequently, the speed of the AFC increases more rapidly than in the case for the DOL start. The effect of the 


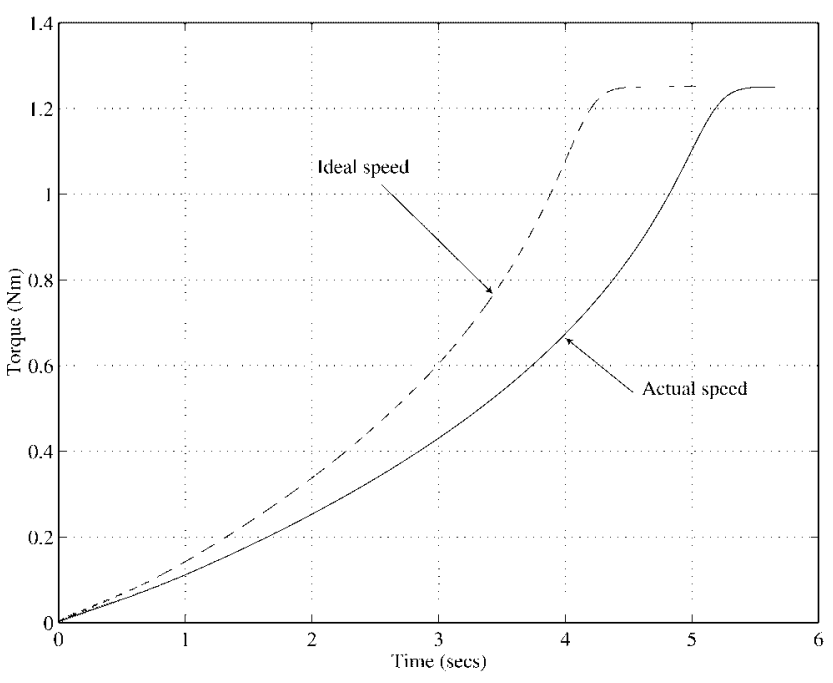

Fig. 14. Chain velocity for a DOL start.

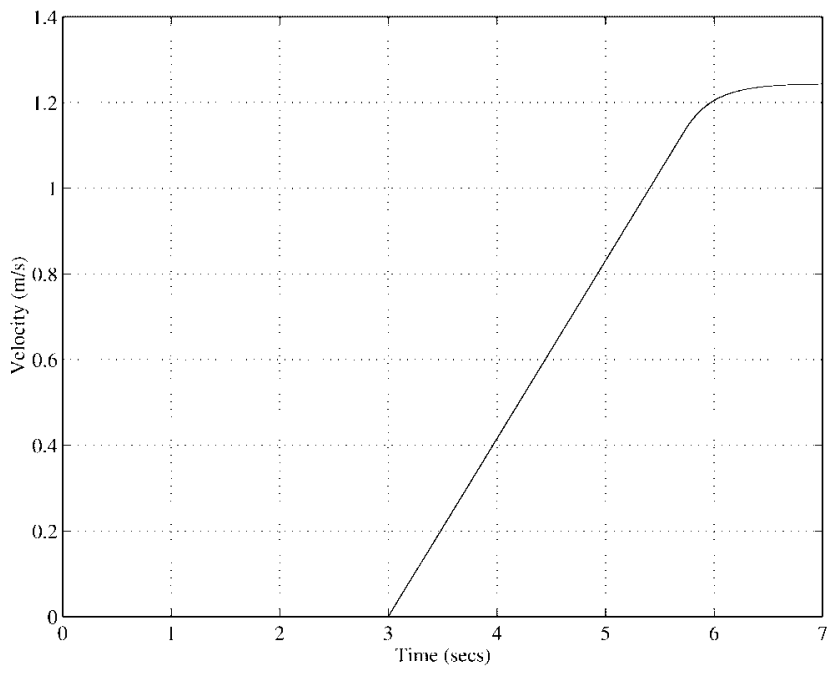

Fig. 15. Chain velocity for the vector-controlled AFC.

better torque performance can be seen from the plots of the chain velocity of the AFC for the two cases. Fig. 14 shows the actual chain velocity and the ideal chain velocity (i.e., with no voltage drop) for a DOL start of the maingate and tailgate machines with a voltage drop between the maingate and the tailgate motors. Notice that the actual chain velocity acceleration profile is approximately $1 \mathrm{~s}$ slower than the ideal case.

Fig. 15 shows the chain velocity curve for the vectorcontrolled machine case with the same impedance in the cable between the maingate and tailgate motors. The acceleration profile is approximately $1 \mathrm{~s}$ faster than the ideal DOL case and $2 \mathrm{~s}$ faster than the actual case. Furthermore, this increased performance for the vector controller has been achieved while maintaining the current to the machines at rated value or below. For the DOL start, the input current is up to seven or eight times the rated current during the acceleration phase.

In all the vector-controlled cases, the torque produced was virtually devoid of torque pulsations relative to that produced by the DOL start. This means that the fluid coupling can be eliminated from the drive system, since the gearbox no longer has to be protected from the motor torque transients.

\section{CONCLUSIONS}

Traditional drive systems for AFC's have a number of problems. Most of these are related to the inability of the drive system to prevent large voltage drops on startup and to account for the various mismatches in the drive system itself. These mismatches result in uneven loading in dual-drive AFC's, which, in turn, results in poor startup performance and undue stress on the drives in steady state.

The performance of the proposed vector-controlled drives can be evaluated based on the control objectives outlined in Section II. We now proceed through these, one by one.

1) As can be seen from the plots in the previous section, under vector control, the maingate and tailgate motors evenly share the load, despite gearbox and voltage supply mismatches.

2) Under conditions of reduced supply, the starting torque would not be reduced with vector control, since, at low speed, the controller usually has ample voltage available to generate full-load torque.

3) The voltage dip at starting is significantly reduced, since the vector controller only requests the normal full-load current for the machines.

4) Resistance to voltage mismatch between the maingate and tailgate motors obtained with vector control also gives a reasonable degree of immunity to externally induced voltage dips in the supply.

5) The high starting torque coupled with the absence of torque transients with the vector-controlled drive means that the fluid coupling can be eliminated from the system. All of the above vector drive simulations have been carried out without the fluid coupling.

6) Speed control of the AFC is implicitly available when vector control is used.

As can be seen from the above, the use of VSD's on the AFC motors should solve all the existing operational problems with longwall AFC's.

From a commercial perspective, this approach eliminates costs incurred due to lost production and component failure. This is probably obtained, however, at the price of higher initial capital expenditure.

\section{REFERENCES}

[1] A. R. Broadfoot and R. E. Betz, "Control problems in armored faced conveyors for longwall mines," this issue, pp. 381-386.

[2] "The assessment of heavy duty conveyors in relation to modern mining systems," Mining Research and Development Establishment, National Coal Board, Burton-on-Trent, U.K., 1980.

[3] A. R. Broadfoot and R. E. Betz, "Prediction of the power requirements for a longwall armored face conveyor," IEEE Trans. Ind. Applicat., vol. 33, pp. 80-89, Jan./Feb. 1997.

[4] A. R. Broadfoot, "Analysis and design of an enhanced longwall armoured face conveyor system," Ph.D. dissertation, Dep. Elect. Comput. Eng., Univ. Newcastle, Newcastle, Australia, 1996.

[5] L. A. Morley, J. L. Kohler, and H. M. Smolnikar, "A model for predicting motor load for an armored face-conveyor drive," IEEE Trans. Ind. Applicat., vol. 24, pp. 649-659, July/Aug. 1988.

[6] P. Vas, Vector Control of AC Machines. London, U.K.: Oxford Univ. Press, 1990.

Alan R. Broadfoot (S'81-M'83), for a photograph and biography, see this issue, p. 386.

Robert E. Betz (M'92), for a photograph and biography, see this issue, p. 354. 